\title{
Biomass burning emission inventory with daily resolution: Application to aircraft observations of Asian outflow
}

\section{Citation}

Heald, Colette L., Daniel J. Jacob, Paul I. Palmer, Mathew J. Evans, Glen W. Sachse, Hanwant B. Singh, and Donald R. Blake. 2003. “Biomass Burning Emission Inventory with Daily Resolution: Application to Aircraft Observations of Asian Outflow." Journal of Geophysical Research 108 (D21). doi:10.1029/2002jd003082.

\section{Published Version}

doi:10.1029/2002JD003082

\section{Permanent link}

http://nrs.harvard.edu/urn-3:HUL.InstRepos:14121759

\section{Terms of Use}

This article was downloaded from Harvard University's DASH repository, and is made available under the terms and conditions applicable to Other Posted Material, as set forth at http:// nrs.harvard.edu/urn-3:HUL.InstRepos:dash.current.terms-of-use\#LAA

\section{Share Your Story}

The Harvard community has made this article openly available.

Please share how this access benefits you. Submit a story.

Accessibility 


\title{
Biomass burning emission inventory with daily resolution: Application to aircraft observations of Asian outflow
}

\author{
Colette L. Heald, ${ }^{1}$ Daniel J. Jacob, ${ }^{1}$ Paul I. Palmer, ${ }^{1}$ Mathew J. Evans, ${ }^{1}$ Glen W. Sachse, ${ }^{2}$ \\ Hanwant B. Singh, ${ }^{3}$ and Donald R. Blake ${ }^{4}$ \\ Received 28 October 2002; revised 4 February 2003; accepted 31 March 2003; published 11 November 2003.
}

[1] We develop a daily-resolved global emission inventory for biomass burning using AVHRR satellite observations of fire activity corrected for data gaps and scan angle biases. We implemented this inventory in a global three-dimensional model (GEOSCHEM) to simulate aircraft CO observations during the TRACE-P mission over the NW Pacific in February-April 2001. Seasonal biomass burning in SE Asia was a major contributor to the outflow of Asian pollution observed in TRACE-P and shows large dayto-day fluctuations that vary depending on location. Three simulations were conducted with the same 3-month total (February-April) emissions but different temporal distributions: 2001 daily resolved, 2001 monthly resolved, and climatological monthly resolved. The effect of daily resolved versus monthly resolved 2001 emissions in the simulation of CO is less than 8 ppbv in Asian outflow over the NW Pacific but can exceed 100 ppbv over source regions. The relatively small effect in Asian outflow reflects spatial and temporal averaging of emissions during ageing in the continental boundary layer. Significant improvement in the simulation of TRACE-P observations (as diagnosed by the resolved variance) is found when using 2001 monthly versus climatological monthly emissions, but using 2001 daily emissions does not offer further improvement. INDEX TERMS: 0322 Atmospheric Composition and Structure: Constituent sources and sinks; 0345 Atmospheric Composition and Structure: Pollution —urban and regional (0305); 0365 Atmospheric Composition and Structure: Troposphere-composition and chemistry; KEYWORDS: biomass burning, TRACE-P, AVHRR, Asia, pollution

Citation: Heald, C. L., D. J. Jacob, P. I. Palmer, M. J. Evans, G. W. Sachse, H. B. Singh, and D. R. Blake, Biomass burning emission inventory with daily resolution: Application to aircraft observations of Asian outflow, J. Geophys. Res., 108(D21), 8811, doi:10.1029/2002JD003082, 2003.

\section{Introduction}

[2] Biomass burning in the tropics is a major source of trace gases and aerosols to the atmosphere [Crutzen and Andreae, 1990; Andreae and Merlet, 2001]. It exhibits large day-to-day variability reflecting weather, agricultural practices, and accidental fires. Previous global three-dimensional (3-D) model studies of tropospheric composition have not accounted for this variability. This may lead to problems when using the models to interpret observed atmospheric concentrations in terms of the magnitude and distribution of biomass burning emissions. We present here an algorithm for resolving the day-to-day variability in biomass burning emissions using space-based fire count data, and we apply it to a 3-D model interpretation of Asian pollution outflow

\footnotetext{
${ }^{1}$ Department of Earth and Planetary Sciences and Division of Engineering and Applied Sciences, Harvard University, Cambridge, Massachusetts, USA.

${ }^{2}$ NASA Langley Research Center, Hampton, Virginia, USA.

${ }^{3}$ NASA Ames Research Center, Moffett Field, California, USA.

${ }^{4}$ Department of Chemistry, University of California, Irvine, Irvine, California, USA.
}

Copyright 2003 by the American Geophysical Union. 0148-0227/03/2002JD003082\$09.00 observed during the NASA Transport and Chemical Evolution over the Pacific (TRACE-P) aircraft mission over the NW Pacific in February-April 2001 [Jacob et al., 2003].

[3] Measurements of fire from space are available from a number of sensors. These include the Along Track Scanning Radiometer (ATSR) [Arino and Rosaz, 1999], the Tropical Rainfall Measuring Mission (TRMM) [Giglio et al., 2000], the Advanced Very High Resolution Radiometer (AVHRR) [Stroppiana et al., 2000] and the Moderate Resolution Imaging Spectrometer (MODIS) [Kaufman et al., 1998]. All of these instruments are presently flying on polarorbiting satellites. Coverage is global but data density can be low, particularly after considering data loss from cloudy scenes. Observations in geostationary orbit would afford higher density, but so far only a few such data sets are available, such as the GOES observations in the Western Hemisphere [Prins et al., 1998]. We use here the AVHRR data, which are available as daily global fire counts for the February-April 2001 period. AVHRR fire observations have been employed previously [Kaufman et al., 1990; Christopher et al., 1998] to make regional estimates of biomass burning emissions.

[4] TRACE-P was conducted at the peak of the biomass burning season in SE Asia and India [Duncan et al., 2003]. 
Biomass burning outflow from SE Asia is transported to the North Pacific primarily by warm conveyor belts ahead of cold fronts at $25-30^{\circ} \mathrm{N}$, and by convective outflow at lower latitudes [Bey et al., 2001b; Liu et al., 2003]. We evaluate our biomass burning inventory and the impact of day-to-day variability for the TRACE-P period with a global 3-D model (GEOS-CHEM) [Bey et al., 2001a] simulation of aircraft observations of carbon monoxide (CO). $\mathrm{CO}$ is a product of incomplete combustion with large sources from both biomass and fossil fuel burning. We also use TRACE-P measurements of $\mathrm{HCN}$ [Singh et al., 2003] and $\mathrm{C}_{2} \mathrm{Cl}_{4}$ [Blake et al., 2003] to separate biomass burning and fossil fuel contributions to the $\mathrm{CO}$ observations.

\section{Construction of Daily Biomass Burning Emission Inventory}

[5] Our approach is to start from a climatological biomass burning emission inventory with $1^{\circ} \times 1^{\circ}$ spatial resolution and monthly temporal resolution [Duncan et al., 2003] and apply day-to-day variability to that inventory for FebruaryApril 2001 using a daily compilation of AVHRR fire count data. Major gaps and biases need to be removed from the AVHRR data, as described below.

\subsection{World Fire Web (WFW) Daily Fire Product}

[6] The AVHRR data employed in this work were obtained from the World Fire Web (WFW) maintained by the Global Vegetation Monitoring Unit at the European Union Joint Research Centre in Italy (available at http:// www.gvm.sai.jrc.it/fire/wfw/wfw.htm). AVHRR is a satellite-borne scanning radiometer which operates in the visible and infrared and was first launched in 1978 aboard TIROS$\mathrm{N}$ [Kidwell, 1998]. Current generations of this instrument are aboard the National Oceanic and Atmospheric Administration (NOAA)-14 and NOAA-15 platforms. Satellite data from AVHRR are processed by a global network of 22 receiving stations or nodes. Daily fire maps assembled by the WFW from these 22 nodes provide nearly global coverage. The data obtained for this study cover FebruaryApril 2001 and were obtained from the NOAA-14 AVHRR instrument. This instrument has a $2400 \mathrm{~km}$ across-track swath and provides global coverage every day with a pixel resolution of $1.1 \times 1.1 \mathrm{~km}$ at nadir and up to $2.4 \times 6.9 \mathrm{~km}$ off-nadir. It orbits the Earth 14 times a day with an 8-day repeat period and has an ascending orbit time of 1340 local time [Kidwell, 1998]. Agricultural fire activity tends to peak in early afternoon [Langaas, 1992] and thus AVHRR is well suited for detecting biomass burning.

[7] The WFW active fire algorithm for AVHRR is presented by Stroppiana et al. [2000] and is based on an examination of absolute temperatures and temperature gradients between neighbouring pixels. It is a modified version of the Flasse and Ceccato [1996] algorithm. Fire counts are registered for hot pixels which emit stronger infrared radiation than their nonfire neighbors. A cloud detection algorithm, based on reflectance and temperature, is applied to identify pixels obscured by cloud. Sun-glint and hotground false detections have been recognised as the principal sources of error [Stroppiana et al., 2000]. The former is caused by reflection of sunlight from nonpermanent water or ice. The latter can be the consequence of heterogeneous
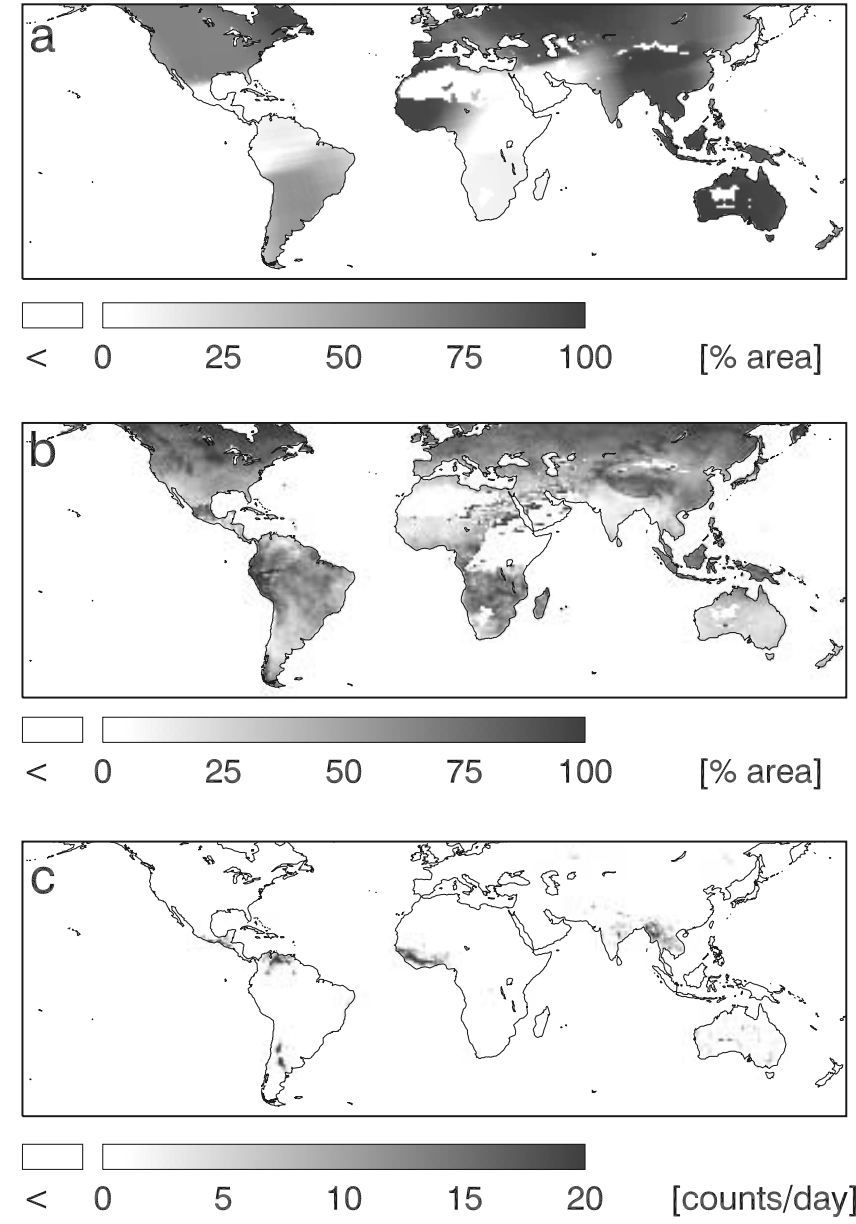

Figure 1. Mean statistics of the AVHRR World Fire Web product for February-April 2001, mapped on a $1^{\circ} \times 1^{\circ}$ grid. (a) Percentage of days with available data; (b) cloud cover; (c) daily fire counts. Blank areas have either no fires or no data. See color version of this figure at back of this issue.

land types where hot and cold pixels are adjacent to one another (e.g., paved highways). Validation of the WFW fire product by Giglio et al. [1999] suggests that while the detection of large fires $\left(>1000 \mathrm{~m}^{2}\right)$ is robust there is greater uncertainty in small fire detection.

[8] The WFW provides a $0.5^{\circ} \times 0.5^{\circ}$ gridded product of fire data which we regridded to $1^{\circ} \times 1^{\circ}$ to match the Duncan et al. [2003] biomass burning inventory. The data include the number of fire counts per grid square $\left(n_{F}\right)$, the number of pixels which are obscured by cloud per grid square $\left(n_{C}\right)$ and the total number of pixels per grid square $\left(n_{T}\right)$ (Figure 1). The WFW product has not been corrected for satellite overpass strip overlap (i.e., double-counting) but we apply this correction through normalization of the data, as described below.

[9] Coverage of the WFW data (Figure 1a) is limited both by the satellite instrument measurement track and by the contributing receiving stations in the network. Receiving stations for eastern and southern Africa and for northern South America did not submit data in February-April 2001. Cloud cover $\left(n_{C} / n_{T}\right)$ is less than $40 \%$ for much of the 

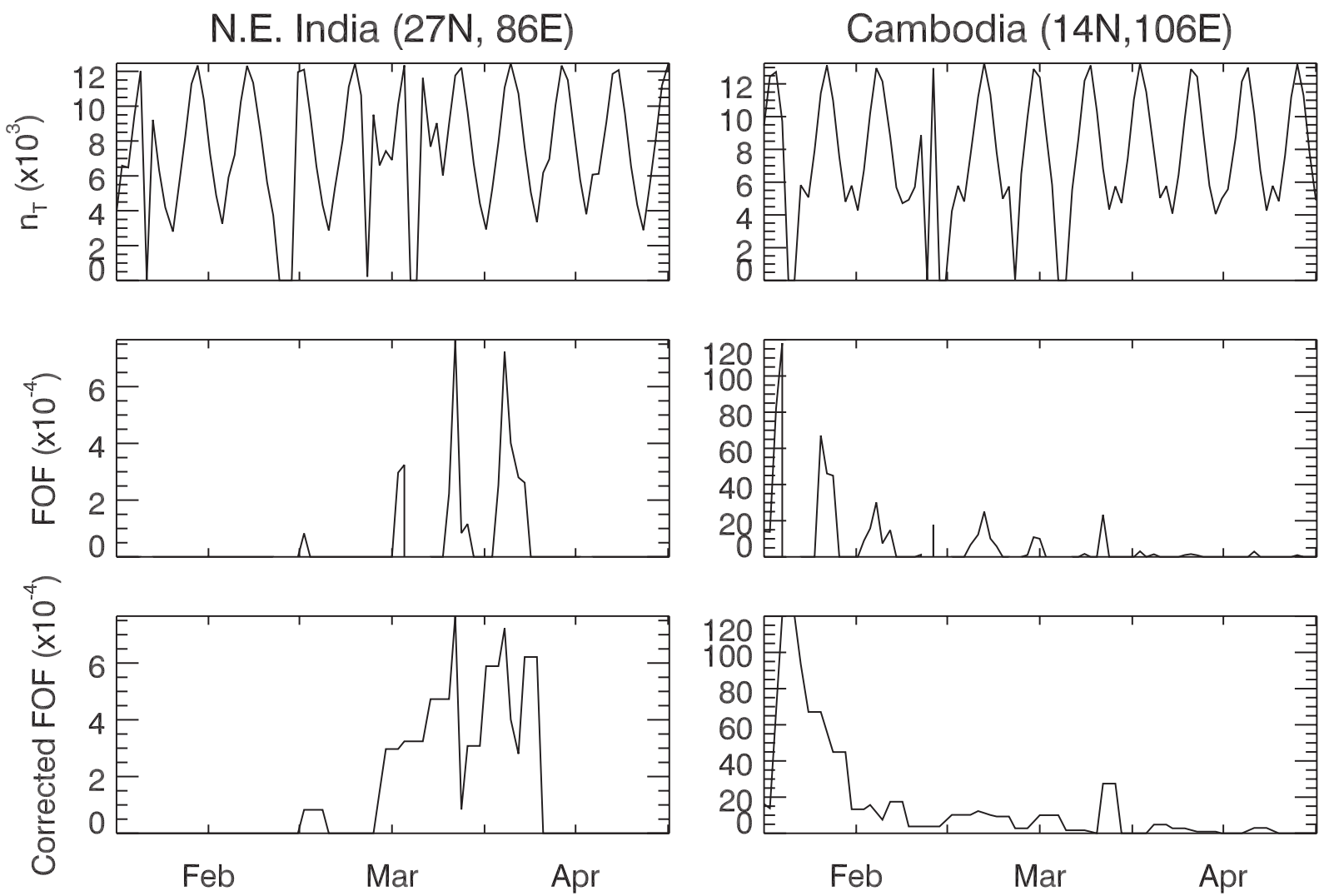

Figure 2. Time series of WFW fire data in two illustrative $1^{\circ} \times 1^{\circ}$ grid squares in SE Asia in FebruaryApril 2001, illustrating the bias in the fire detection algorithm for off-nadir viewing. The top panels show the total number of WFW data pixels for each grid square; off-nadir scenes have fewer pixels because of the viewing angle (see text). The middle panels show the normalized Fraction on Fire (FOF) as given in equation (1); the 8-day periodicity and the lack of fire detection for off-nadir scenes reflect the scan angle bias. The bottom panel shows the FOF after correction for the bias (see text).

northern tropics (dry season), including SE Asia and India. Comparison with the International Satellite Cloud Climatology (available at http://isccp.giss.nasa.gov/) indicates that extensive clouds are erroneously reported in the AVHRR product over high northern latitudes. This is likely due to reflection from snow and ice.

[10] Cloudy pixels may contain wet vegetation which does not readily burn, however fire activity has been observed in persistently cloudy regions [Robinson, 1991]. In the absence of evidence to the contrary, we assume that the probability of fires in cloudy pixels for a given $1^{\circ} \times 1^{\circ}$ square is the same as in clear-sky pixels. The resulting Fraction On Fire (FOF) for the $1^{\circ} \times 1^{\circ}$ grid square is calculated as:

$$
F O F=\frac{n_{F}}{n_{T}-n_{c}}
$$

This approach corrects not only for clouds but also for double counting when polar orbital tracks overlap. FOF values in fires regions are typically in the $10^{-4}-10^{-2}$ range. We do not calculate FOF values for grid squares with cloud fractions greater than $90 \%$, because of excessive uncertainty.

\subsection{Correction of Scan Angle Bias}

[11] Our initial analysis of the WFW fire data revealed a bias in the fire detection efficiency for the off-nadir pixels.
This bias is illustrated for two scenes in Figure 2. Nadir view for a given scene occurs only every 8 days. As scan angle increases, the coverage, or the total number of pixels observed, decreases (Figure 2, top panel) [Frulla et al., 1995]. This decrease simply reflects the viewing geometry and should not affect the FOF. However, we find that the FOF peaks for nadir viewing and drops to near zero at large scan angles (Figure 2, middle panel), reflecting a bias in the detection efficiency previously identified qualitatively by Giglio et al. [1999]. This is further illustrated in Figure 3 (top panel), which shows the probability of nonzero FOF in a $1^{\circ} \times 1^{\circ}$ grid square as a function of the number of pixels viewed $\left(n_{T}\right)$ for the ensemble of the East Asian region (10$\left.50^{\circ} \mathrm{N}, 70-160^{\circ} \mathrm{E}\right)$ in February-April 2001. Nadir viewing yields $n_{T}=1.25 \times 10^{4}$ daily pixel observations per $1^{\circ} \times 1^{\circ}$ grid square. Low values of $n_{T}$ are associated with high scan angles. Values of $n_{T}>1.25 \times 10^{4}$ reflect double counting and are also associated with large scan angles. For $n_{T}$ values within the near-nadir range $\left[1 \times 10^{4}, 1.25 \times 10^{4}\right]$, the probability of nonzero FOF is within $50 \%$ of that for the nadir view.

[12] The bottom panel of Figure 3 shows the mean values of FOF as a function of $n_{T}$ for the subset of grid squares with nonzero FOF. A linear relationship is found for $n_{T}$ in the range $\left[5 \times 10^{3}, 1.25 \times 10^{4}\right]$, implying that nonzero FOF values observed within that $n_{T}$ range provide useful infor- 

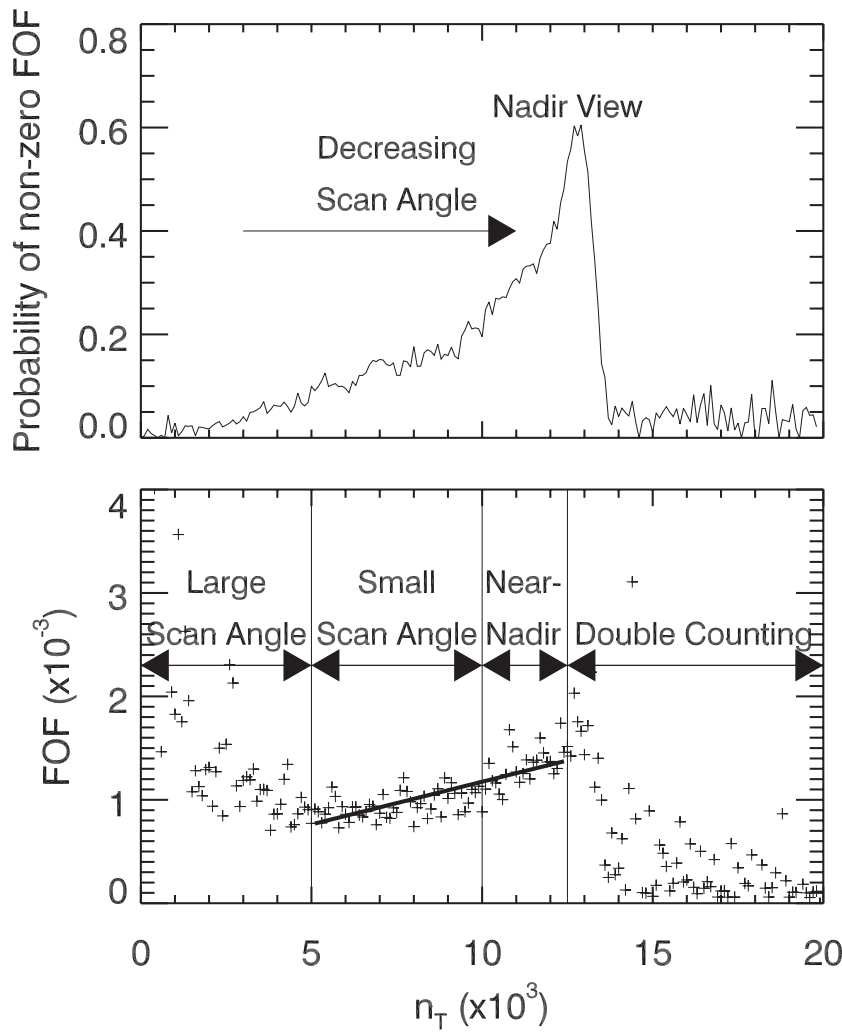

Figure 3. Dependence of fraction on fire (FOF) statistics on AVHRR viewing angle for all $1^{\circ} \times 1^{\circ}$ grid squares in SE Asia $\left(10-50^{\circ} \mathrm{N}, 70-160^{\circ} \mathrm{E}\right)$ during February-April 2001. The abscissa gives the number $\left(n_{T}\right)$ of AVHRR observations in the grid square, which is directly related to scan angle; $n_{T}$ increases up to $1.25 \times 10^{4}$ as the scan angle decreases down to nadir. Higher values of $n_{T}$ reflect double counting and are associated with large scan angles. Top panel: Probability of nonzero FOF in a $1^{\circ} \times 1^{\circ}$ grid square. The probability increases with decreasing scan angle. Bottom panel: mean value of the FOF for those gridsquares where fires were detected, binned over $\Delta n_{T}=100$ intervals. The linear regression applied to the data in the $n_{T}$ range $\left[5 \times 10^{3}\right.$, $\left.1.25 \times 10^{4}\right]$ is also shown.

mation on fires that can be normalized to the nadir view with the linear regression shown in the figure.

[13] On the basis of the above discussion we exclude from the data set all observations for which $n_{T}$ is outside the range $\left[5 \times 10^{3}, 1.25 \times 10^{4}\right]$, and all observations of zero FOFs outside the range $\left[1 \times 10^{4}, 1.25 \times 10^{4}\right]$. We apply the linear regression of Figure 3 to normalize all nonzero FOF values in the $n_{T}$ range $\left[5 \times 10^{3}, 1.25 \times 10^{4}\right]$ to the equivalent nadir value. Our filter reduces the number of usable daily fire observations by $78 \%$; for every 8 -day period of data there are typically only 2 usable days. In order to address this data gap and obtain a continuous global data set for fire occurrence, we adopted a persistence model for fire activity. Data gaps were filled with the most recent observed values, either forward or backward in time up to 8 days (one repeat cycle) away. We assume that the fire product provides no information for data gaps beyond 8 days; such situations are found only in regions of infrequent fire or regions where no AVHRR data are available (Figure 1). Figure 2 (bottom panel) shows the corrected FOF product for the two illustrative sites grid squares.

\subsection{Construction of Daily Emission Inventory}

[14] We apply the daily global distribution of FOFs from section 2.2 to impose a day-to-day variability for FebruaryApril 2001 to the climatological biomass burning emission inventory from Duncan et al. [2003]. This inventory, originally described by Lobert et al. [1999], is based on data from the last 15 years for savannah burning, deforestation, forest fires, shifting agriculture, the burning of shrub and grassland, and burning in fields. It includes seasonal variation with monthly resolution prescribed from a 5-year record of ATSR and AVHRR fire observations. The global emission of $\mathrm{CO}$ is $437 \mathrm{Tg} \mathrm{CO} \mathrm{yr}^{-1}$; approximately $50 \%$ of February-April emissions are in Asia (Figure 4).

[15] Duncan et al. [2003] employed the TOMS Aerosol Index (AI) [Herman et al., 1997] to quantify the 19792001 interannual variability in biomass burning emissions. Figure 5 shows that burning in SE Asia in February-April 2001 was $87 \%$ of the climatological average, although there are large month-to-month departures as described below. The TOMS AI does not provide useful information on interannual variability in biomass burning over India due to excessive anthropogenic haze.

[16] We assume here that the geographical distribution of the 3-month average emissions for February-April 2001 is that given by the climatology and we use our FOF product to distribute the emissions temporally over these three months. For regions with less than 5 days of nonzero FOF data for February-April 2001, we default to a 31-day running average of the climatological emissions. This affects mainly eastern Africa and northern South America (Figure 1). Figure 6 shows the resulting emissions of $\mathrm{CO}$ for three regions in SE Asia and India. There is large day-to-day variability as well as significant, regionally variable departures of the 2001 monthly means from the climatology (Figure 4). Emissions in March 2001 were generally less than the climatology, while emissions in February 2001 were slightly higher.

\section{Application to CO Simulation in Asian Outflow}

[17] We used our daily resolved biomass burning emission inventory in a global 3-D model to simulate observations of $\mathrm{CO}$ concentrations during TRACE-P, and we compared with results from simulations using climatological and 2001 monthly resolved emissions. The simulations were done using the GEOS-CHEM model [Bey et al., 2001a; Martin et al., 2002] driven by assimilated meteorological data from the Goddard Earth Observing System (GEOS)-3 of the NASA Data Assimilation Office (DAO). The original GEOS-3 meteorological data have $1^{\circ} \times 1^{\circ}$ horizontal resolution. We use here GEOS-CHEM v. 4.20 (available at http://www-as.harvard.edu/chemistry/trop/ geos) with a $2^{\circ}$ latitude by $2.5^{\circ}$ longitude resolution and 48 vertical sigma levels. Applications of GEOS-CHEM to different aspects of the TRACE-P observations are presented by C.L. Heald et al. (Asian outflow and transpacific transport of carbon monoxide and ozone pollution: An integrated satellite, aircraft, and model perspective, submitted to Journal of Geophysical Research, 2003), Li et al. 

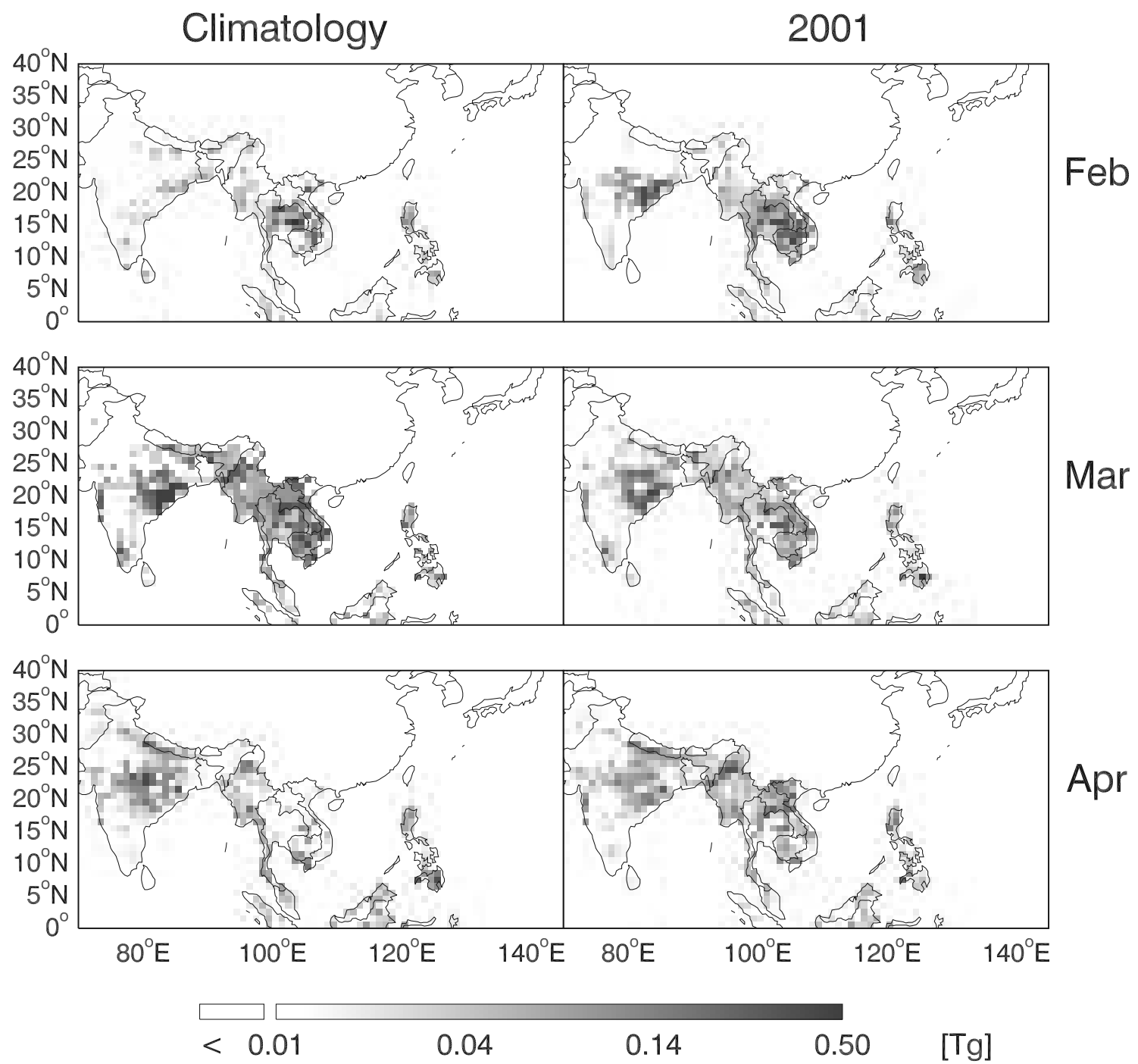

Figure 4. Climatological [Duncan et al., 2003] and 2001 AVHRR-derived monthly total CO emissions from biomass burning in East Asia in February-April. See color version of this figure at back of this issue.

[2003], Liu et al. [2003], and Palmer et al. [2003]. Kiley et al. [2003] present an evaluation of the GEOS-CHEM simulation of CO transport in TRACE-P and compare it to that of other 3-D models used in TRACE-P.

[18] We conducted a CO-only simulation with specified monthly mean $\mathrm{OH}$ fields as described by Bey et al. [2001b]. The CO source is from B.N. Duncan et al. (manuscript in preparation, 2003) and is an improved version of that described by Bey et al. [2001a]. Sources of CO from fossil fuel, biofuel, and biomass burning include both direct emissions and chemical production from the oxidation of methane and nonmethane volatile organic compounds (NMVOCs); the latter is accounted for by appropriate scaling of the $\mathrm{CO}$ emissions. The $\mathrm{CO}$ originating from biomass burning, biofuels, and fossil fuels is transported as separate tracers, as in the work of Bey et al. [2001b]. A 1 -year simulation is used to ensure proper initialization.

[19] We describe results from three simulations. The first uses climatological biomass burning emissions with a monthly temporal resolution and will be referred to as "climatological monthly" in the remainder of this paper. The simulations which employ the 2001 AVHRR-defined emissions with monthly and daily resolution will be referred to as "2001 monthly" and "2001 daily," respectively. Our total biomass burning emissions for East Asia (the domain of Figure 4) in spring 2001 are $20.8 \mathrm{Tg}$ CO in February, 25.4 Tg CO in March, and 23.1 Tg CO in April.

[20] The mean simulated $\mathrm{CO}$ concentrations over the TRACE-P period and the mean absolute differences between the 2001 monthly and 2001 daily model simulations are shown in Figure 7 for three different altitudes. Mean absolute differences were calculated by taking absolute differences in model output sampled every 3 hours and averaging them over the TRACE-P deployment period (25 February-10 April). Biomass burning outflow to the Pacific is mainly restricted to the free troposphere at $15-30^{\circ} \mathrm{N}$ [Liu et al., 2003]. Mean absolute differences are typically $4-8 \mathrm{ppbv}$ in the free troposphere outflow (10-20\% of biomass burning CO concentrations) and up to $100 \mathrm{ppbv}$ in the continental source region. For the ensemble of conditions observed by the TRACE-P aircraft, the model sampled along the flight tracks shows less than $10 \mathrm{ppbv}$ difference between the 2001 daily and monthly simulations in $91 \%$ of cases and at most a $30 \mathrm{ppbv}$ difference 


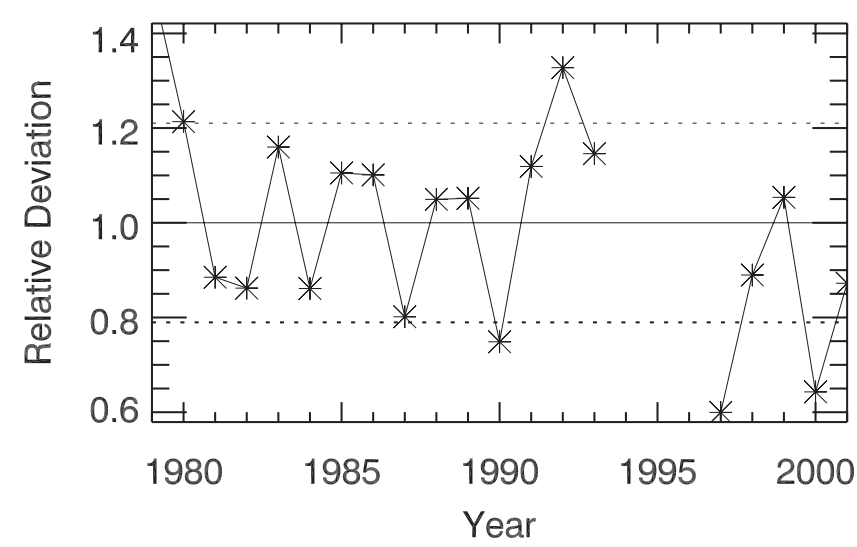

Figure 5. Interannual variability of fire activity in SE Asia (9-29N, 96-119E) for the 3-month period February-April as measured by the TOMS Aerosol Index (1979-2001) [Duncan et al., 2003]. The figure shows the relative deviation from the climatological mean (standard deviation is shown as dashed lines). The data gap from 1994 to 1996 is due to the interruption of TOMS observations between the decommissioning of the Nimbus-7 TOMS and the launch of the Earth-Probe TOMS instrument. The TOMS Aerosol Index for 2001 is a factor of 0.87 lower than climatology, within one standard deviation of 0.21 .

(Figure 8). The relatively small effect reflects the spatial and temporal averaging of biomass burning influences during the aging of air masses in the continental boundary layer.

[21] Point-by-point comparison of model results to the ensemble of aircraft observations west of the dateline and south of $30^{\circ} \mathrm{N}$ is shown as a scatterplot in Figure 9. Model simulations were sampled along the aircraft flight track, and observations along the flight track were averaged over model gridboxes. The climatological monthly simulation shows an $\mathrm{R}^{2}$ of 0.46 compared to the improved $\mathrm{R}^{2}(0.52)$ achieved with the 2001 monthly simulation. The 2001 daily simulation does not capture any more variability in the observations $\left(\mathrm{R}^{2}=0.51\right)$ than the 2001 monthly simulation. The lack of improvement in $\mathrm{R}^{2}$ between the 2001 monthly and daily simulations reflects the small differences between the two simulations (Figure 8) and also model transport errors in lifting biomass burning effluents to the free troposphere [Kiley et al., 2003]. Inadequate resolution of individual convective events may limit the advantage to be gained from fine temporal resolution of emissions. The regressions in Figure 8 indicate a low bias in the model which may reflect a combination of errors associated with the anthropogenic and biomass burning sources, and with the magnitude of the $\mathrm{OH}$ sink. Further discussion of the constraints from the model simulation on sources during TRACE-P is given in the work of Palmer et al. [2003]. Palmer et al. [2003] use a lower OH concentration (GEOSCHEM v. 4.33) than we do here, resulting in a higher background $\mathrm{CO}$ concentration.

[22] Air masses sampled during TRACE-P represented a complicated mixture of source types [Liu et al., 2003]. Our model simulations suggest that biomass burning contributed approximately $30 \%$ of the $\mathrm{CO}$ observed south of $30^{\circ} \mathrm{N}$ during TRACE-P. Further assessment of the effect of daily resolution of biomass burning emissions in our model can be made by isolating the biomass burning component of $\mathrm{CO}$ in the observations. For this purpose we use the urban tracer perchloroethene (PCE) [Blake et al., 2003] and the biomass burning tracer hydrogen cyanide (HCN) [Singh et al., 2003; Li et al., 2003]. Both PCE and HCN have atmospheric lifetimes of the order of months [Blake et al., 1996; Li et al., 2000].

[23] We find that a multivariable linear fit of $\mathrm{CO}$ to $\mathrm{PCE}$ and $\mathrm{HCN}$ accounts for $77 \%$ of the observed variability of $\mathrm{CO}$ in the 5-min average data west of the dateline and above $2 \mathrm{~km}$ altitude (where most of the biomass burning influence was observed) (Figure 10). Single-variable fits to PCE and HCN can account for $58 \%$ and $38 \%$ of the variability, respectively. From the linear relationship $[\mathrm{CO}]=a[\mathrm{PCE}]$ $+b[\mathrm{HCN}]+c$ with coefficients $a, b$, and $c$ as given in Figure 10, we estimate the biomass burning contribution to the 5-min $\mathrm{CO}$ average concentrations as the corresponding value of $b[\mathrm{HCN}]$. Figure 11 shows that the improvement in the quality of the simulation (as measured by $\mathrm{R}^{2}$ ) when using

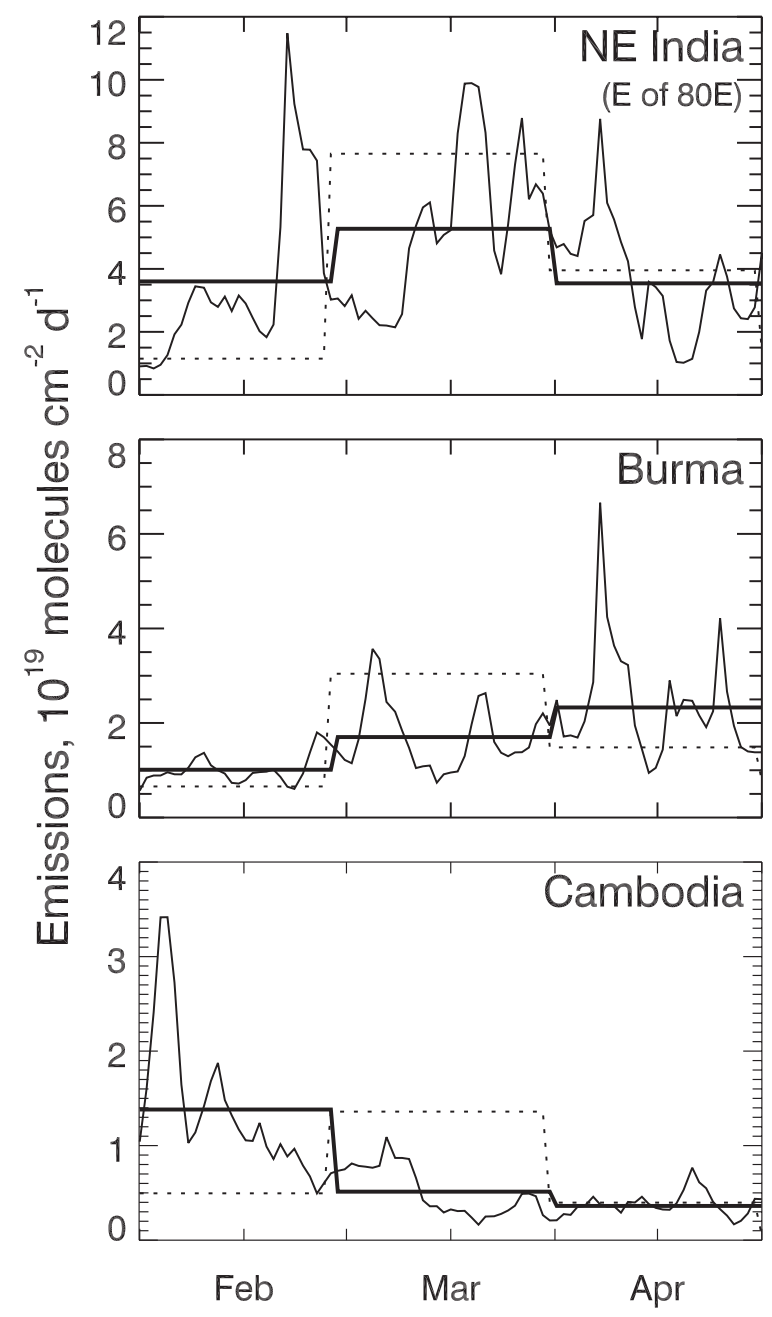

Figure 6. Total daily $\mathrm{CO}$ emissions from biomass burning in February-April 2001 for 3 regions: NE India, Burma, and Cambodia. Daily emissions are shown as the thin solid line, monthly average emissions as a thick solid line and climatological monthly emissions [Duncan et al., 2003] as the dotted line. 

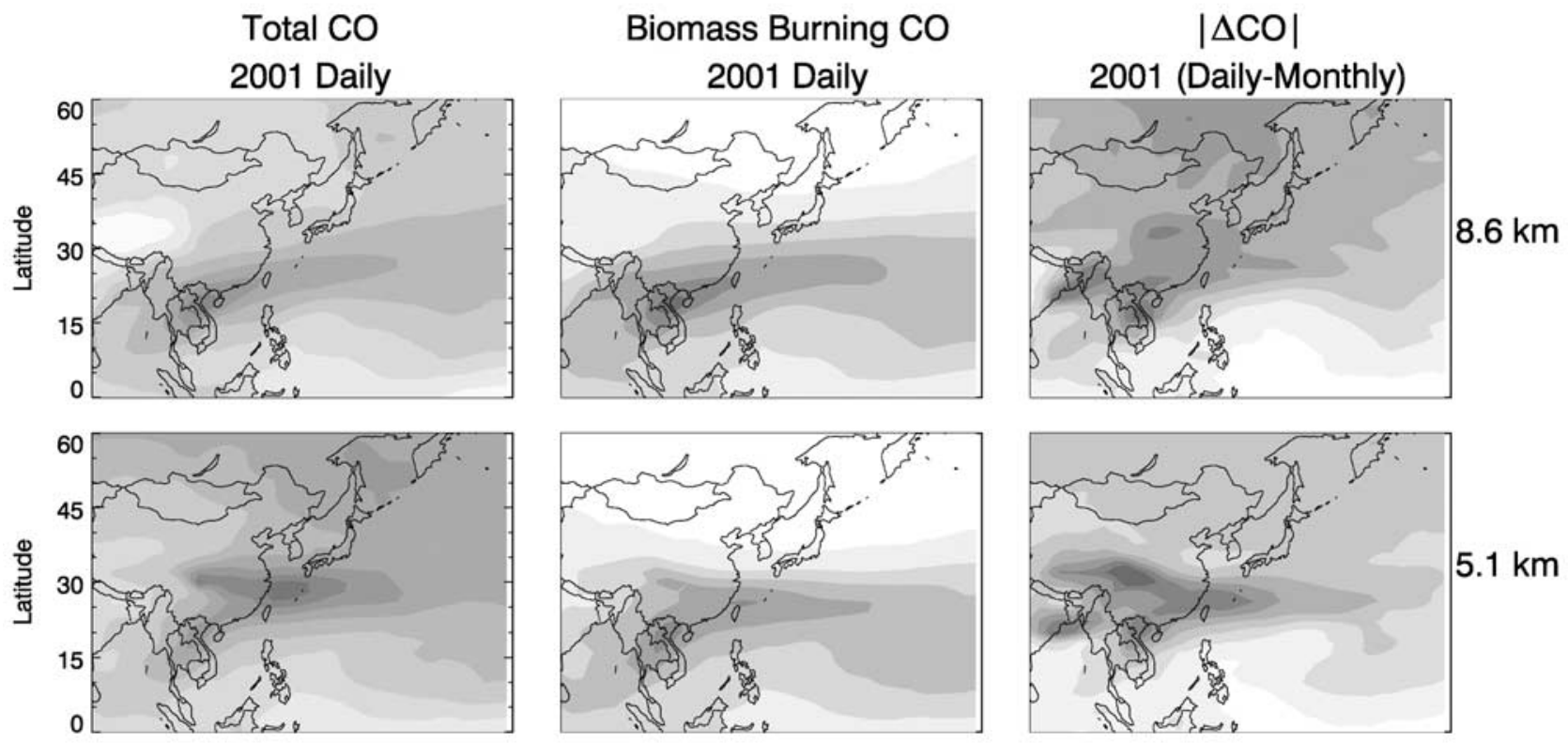

$5.1 \mathrm{~km}$
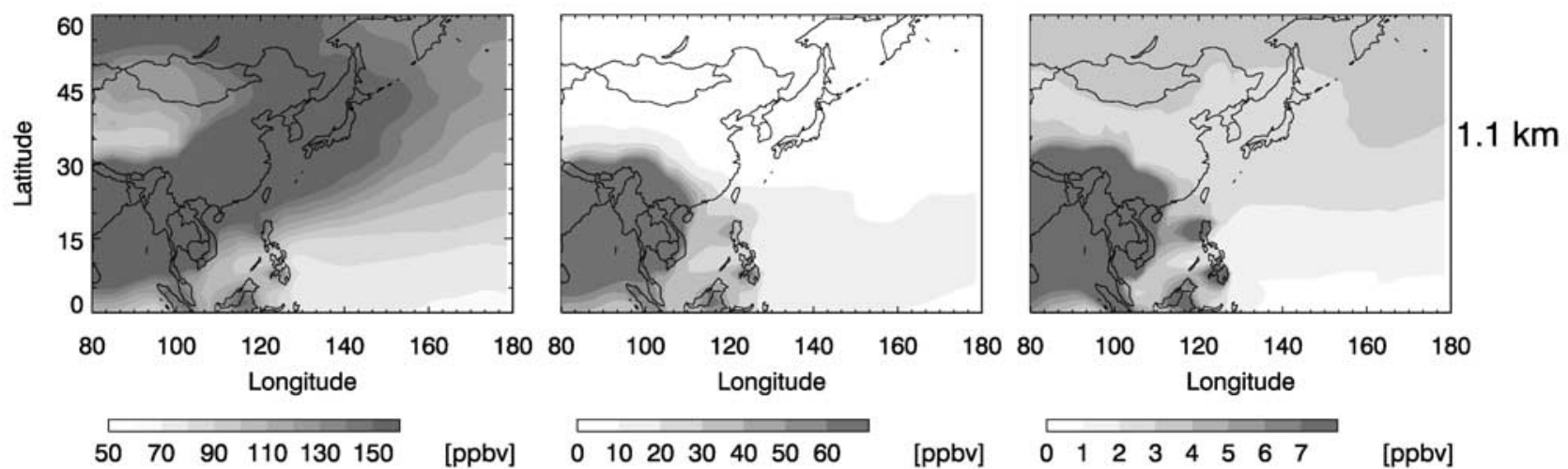

Figure 7. Simulated CO concentrations for the TRACE-P deployment period (25 February-10 April 2001) and effect of daily resolved biomass burning emissions. Left panels: mean CO concentrations at different altitudes in the 2001 daily simulation. The color bar is saturated at $150 \mathrm{ppbv}$ to emphasize the structure of the Asian outflow over the western Pacific sampled by TRACE-P; surface values over Asia can exceed 600 ppbv. Middle panels: mean biomass burning CO concentrations. The color bar is saturated at 60 ppbv. Right panels: average absolute differences between CO concentrations in the 2001 monthly and 2001 daily simulations. Color bar is saturated at 8 ppbv; absolute differences over Asia can exceed 120 ppbv. See color version of this figure at back of this issue.

2001 rather than climatological monthly emissions increases as the biomass burning contribution to $\mathrm{CO}$ in the observations increases. Again, the 2001 daily simulation does not improve significantly over the 2001 monthly simulation.

\section{Conclusions}

[24] We developed an approach for incorporating daily variability into a biomass burning emission inventory by using global satellite observations of fire activity. We used for this purpose the daily AVHRR WFW satellite data. Our initial analysis revealed a scan angle bias in these data, which we corrected but at the loss of over half of the data. The corrected fire product was employed to produce a daily biomass burning inventory for the spring of 2001. Most of the burning during that season is in East Asia, and we find large daily variability in biomass burning emissions with different patterns within the region. The daily resolved biomass burning inventory was incorporated in a global 3-D chemical tracer model (GEOS-CHEM) and used to simulate observed $\mathrm{CO}$ concentrations in Asian outflow over the NW Pacific from the TRACE-P aircraft mission (February-April 2001). We find that accounting for the daily variability of biomass burning in the model modifies $\mathrm{CO}$ concentrations by up to $8 \mathrm{ppbv}$ in Asian outflow over the NW Pacific and by 100 ppbv or more in continental source regions, relative to a simulation using monthly mean emissions.

[25] We conducted three model simulations for February-April 2001 with the same 3-month totals of biomass burning emissions but with different temporal resolutions: daily resolved for 2001, monthly resolved for 2001, and monthly resolved climatological. Our CO simulation using monthly resolved biomass burning emissions for 2001 


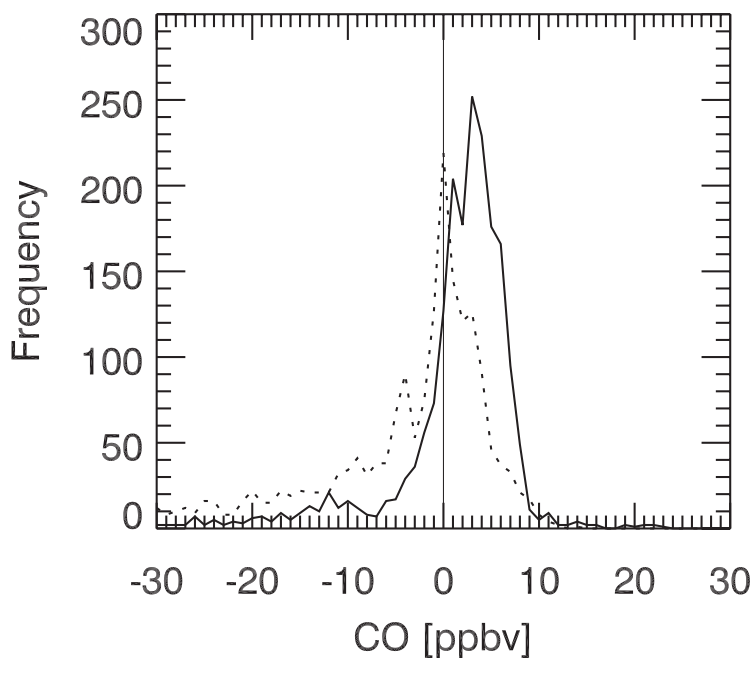

Figure 8. Effect of daily and interannual variability in biomass burning emissions on the GEOS-CHEM model simulation of $\mathrm{CO}$ concentrations sampled along the TRACE-P flight tracks south of $30^{\circ} \mathrm{N}$. The figure shows frequency distributions of the difference between the 2001 monthly and 2001 daily simulations (solid line; mean difference $1.5 \mathrm{ppbv}$ ) and the difference between the 2001 monthly and climatological monthly simulations (dotted line; mean difference $-6.8 \mathrm{ppbv}$ ).

shows some improvement in the simulation of TRACE-P aircraft observations relative to the simulation with monthly resolved climatology ( $\mathrm{R}^{2}$ increases from 0.46 to 0.52 ). The improvement is particularly pronounced for the TRACE-P

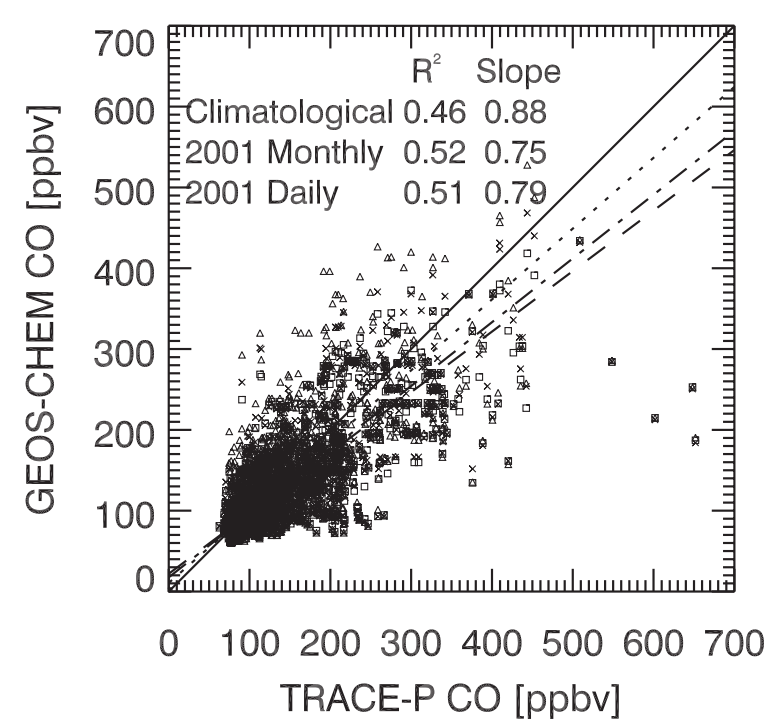

Figure 9. Point-by-point comparison of GEOS-CHEM model results to the ensemble of TRACE-P aircraft observations south of $30^{\circ} \mathrm{N}$ and west of the dateline. The lines of best fit for the climatological monthly (black) 2001 monthly (red) and 2001 daily (blue) simulations are shown. The one-to-one line is shown in dotted black. Statistics were computed with the reduced-major-axis method [Hirsch and Gilroy, 1984]. See color version of this figure at back of this issue.

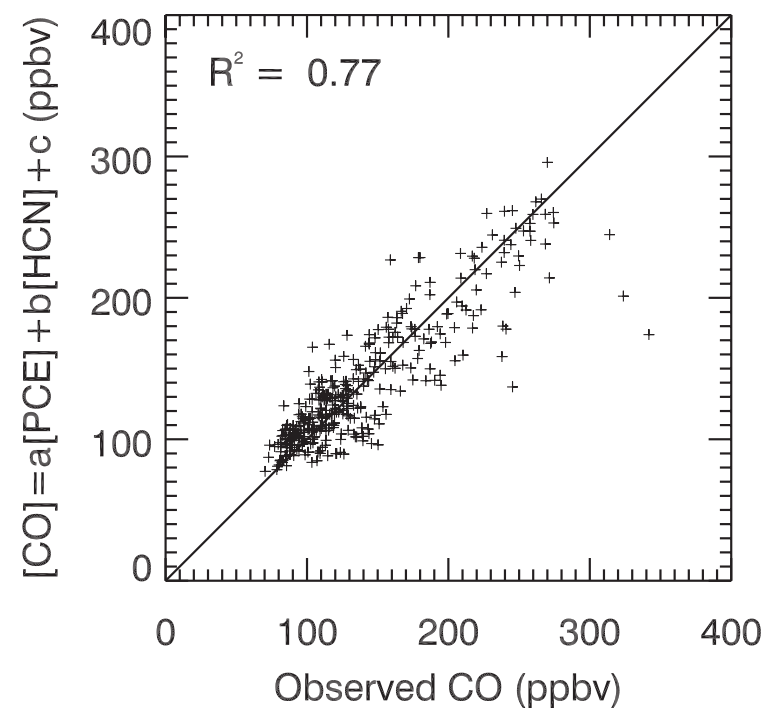

Figure 10. Linear fit of $\mathrm{CO}$ to $\mathrm{PCE}$ and $\mathrm{HCN}$ concentrations for the TRACE-P data subset above $2 \mathrm{~km}$ altitude, west of the dateline and excluding stratospheric air. The fit is $[\mathrm{CO}]=a[\mathrm{PCE}]+b[\mathrm{HCN}]+c$, where $a=9.96 \times 10^{-3}$, $b=270$ and $c=24.5 \mathrm{ppbv}$.

data subset most heavily influenced by biomass burning. There is no further improvement in the simulation of observations when the daily resolved 2001 inventory is employed. We attribute this result in part to the spatial and temporal averaging of biomass burning influences in the free tropospheric outflow over the NW pacific sampled in TRACE-P and in part to model transport noise that limits

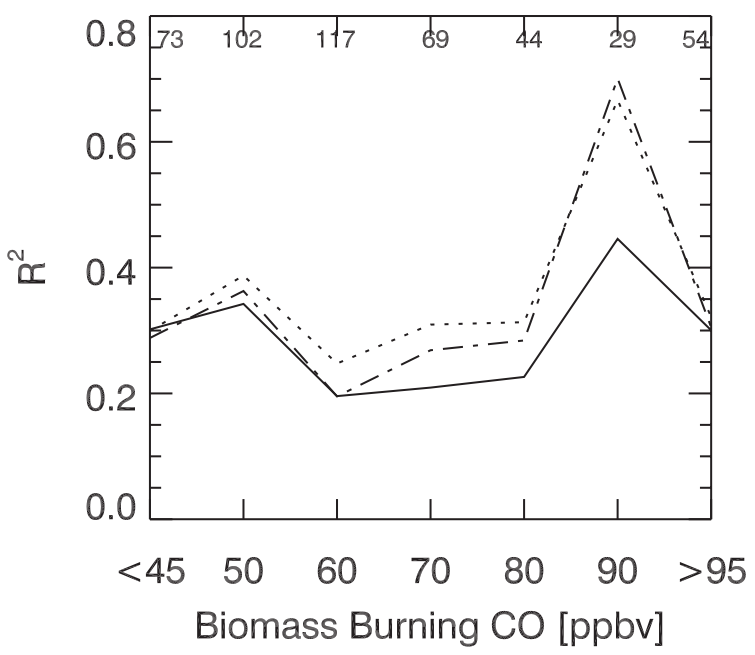

Figure 11. Correlation between simulated (GEOSCHEM) and observed (DC-8) CO concentrations as a function of the biomass burning $\mathrm{CO}$ concentration identified from the observations by linear fit to PCE and $\mathrm{HCN}$ concentrations (see text). Results from the simulation with climatological monthly emissions (solid) are compared with those using 2001 monthly emissions (dashed) and 2001 daily emissions (dash-dot). The numbers across the top of the figure indicate the number of points in each averaging interval. 
the advantage to be gained from fine temporal resolution of emissions.

[26] Our results indicate that daily resolution of biomass burning emissions is not critical for modeling outflow from tropical regions on a global scale. Such resolution is certainly more important when simulating large isolated wildfire events [Wotawa and Trainer, 2000] or when interpreting satellite observations of biomass burning effluents [Thomas et al., 1998, Spichtinger et al., 2001]. Bottomup inventories based on satellite observations of burned areas and vegetative cover [Michel et al., 2002] may offer a more accurate picture of biomass burning emissions in the future.

[27] Acknowledgments. This work was supported by the NASA Global Tropospheric Chemistry Program. CLH was supported in part by the Natural Science and Engineering Research Council of Canada and the Canadian Space Agency. We would like to express our appreciation to Simon Pinnock for his assistance in obtaining the AVHRR data and to Bryan Duncan for providing the TOMS AI climatology for Southeast Asia. We would also like to acknowledge the helpful comments of two reviewers.

\section{References}

Andreae, M. O., and P. Merlet, Emission of trace gases and aerosols from biomass burning, Global Biogeochem. Cycles, 15, 955-966, 2001

Arino, O. J., and M. Rosaz, 1997 and 1998 World ATSR Fire Atlas Using ERS-2 ATSR-2 Data, in Proceedings of the Joint Fire Science Conference, pp. 177-182, Univ. of Idaho, Boise, 1999.

Bey, I., D. J. Jacob, R. M. Yantosca, J. A. Logan, B. D. Field, A. M. Fiore, Q. Li, H. Liu, L. J. Mickley, and M. G. Schultz, Global modeling of tropospheric chemistry with assimilated meteorology: Model description and evaluation, J. Geophys Res., 106, 23,073-23,095, 2001a.

Bey, I., D. J. Jacob, J. A. Logan, and R. M. Yantosca, Asian chemical outflow to the Pacific in spring: Origins, pathways, and budgets, J. Geophys. Res., 106, 23,097-23,113, 2001b.

Blake, D. R., T.-Y. Chen, T. W. Smith Jr., C. J.-L. Wang, O. W. Wingenter, N. J. Blake, and F. S. Rowland, Three-dimensional distribution of nonmethane hydrocarbons and halocarbons over the north-western Pacific during the 1991 Pacific Exploratory Mission (PEM-West A), J. Geophys. Res., 101, 1763-1778, 1996.

Blake, N. J., et al., NMHCs and Halocarbons in Asian Outflow during TRACE-P: Comparison to PEM-West B, J. Geophys. Res., 108(D20), 8806, doi:10.1029/2002JD003367, in press, 2003.

Christopher, S. A., J. Chou, R. M. Welch, D. V. Kliche, and V. S. Connors, Satellite investigations of fire, smoke, and carbon monoxide during 1994 MAPS mission: Case studies over tropical Asia, J. Geophys. Res., 103, 19,327-19,336, 1998.

Crutzen, P. J., and M. O. Andreae, Biomass burning in the tropics-Impact on atmospheric chemistry and biogeochemical cycles, Science, 250, $1669-1678,1990$.

Duncan, B. N., R. V. Martin, A. C. Staudt, R. Yevich, and J. A. Logan, Interannual and seasonal variability of biomass burning emissions constrained by satellite observations, J. Geophys. Res., 108(D9), 4040, doi:10.1029/2002JD002378, 2003.

Frulla, L. A., J. A. Milovich, and D. A. Gagliardini, Illumination and observation geometry for NOAA-AVHRR images, Int. J. Remote Sens., $16,2233-2253,1995$.

Giglio, L., J. D. Kendall, and C. O. Justice, Evaluation of global fire detection algorithm using simulated AVHRR infrared data, Int. J. Remote Sens., 20, 1947-1985, 1999.

Giglio, L., J. D. Kendall, and C. J. Tucker, Remote sensing of fires with the TRMM VIRS, Int. J. Remote Sens., 21, 203-207, 2000.

Herman, J. R., P. K. Bhartia, O. Torres, C. Hsu, C. Seftor, and E. Celarier, Global distributions of UV-absorbing aerosols from Nimbus 7/TOMS data, J. Geophys. Res., 102, 16,911-16,922, 1997.

Hirsch, R. M., and E. J. Gilroy, Methods of fitting a straight line to data: Examples in water resources, Water Res. Bull., 20, 705-711, 1984.

Jacob, D. J., J. H. Crawford, M. M. Kleb, V. E. Connors, R. J. Bendura, J. L. Raper, G. W. Sachse, J. C. Gille, L. Emmons, and C. L. Heald, The Transport and Chemical Evolution over the Pacific (TRACE-P) aircraft mission: Design, execution, and first results, J. Geophys. Res., 108(D20), 8781, doi:10.1029/2002JD003276, in press, 2003.

Kaufman, Y. J., C. J. Tucker, and I. Fung, Remote sensing of biomass burning in the tropics, J. Geophys. Res., 95, 9927-9939, 1990.
Kaufman, Y. J., C. O. Justice, L. P. Flynn, J. D. Kendall, E. M. Prins, L. Giglio, D. E. Ward, W. P. Menzel, and A. W. Setzer, Potential global fire detection from EOS-MODIS, J. Geophys. Res., 103, 32,215-32,238, 1998.

Kidwell, K. B., NOAA Polar Orbiter Data (TIROS-N, NOAA-6, NOAA-7, NOAA-8, NOAA-9, NOAA-10, NOAA-11, NOAA-12, NOAA-13 and NOAA-14) Users Guide, NOAA/NESDIS, Washington, D.C., 1998.

Kiley, C. M., et al., An intercomparison and validation of aircraft-derived and simulated $\mathrm{CO}$ from seven chemical transport models during the TRACE-P experiment, J. Geophys. Res., 108(D21), 8819, doi:10.1029/ 2002JD003089, in press, 2003.

Langaas, S., Temporal and spatial distribution of savanna fires in Senegal and the Gambia, West Africa, 1989-90, derived from multi-temporal AVHRR night images, Int. J. Wildland Fire, 2, 21-36, 1992.

Li, Q., D. J. Jacob, I. Bey, R. M. Yantosca, Y. Zhao, Y. Kondo, and J. Notholt, Atmospheric hydrogen cyanide $(\mathrm{HCN})$ : Biomass burning source, ocean sink?, Geophys. Res. Lett., 27, 357-360, 2000.

Li, Q., D. J. Jacob, R. M. Yantosca, C. L. Heald, H. B. Singh, G. W. Sachse, D. G. Streets, M. Koike, and Y. Zhao, A global three-dimensional model evaluation of the atmospheric budgets of $\mathrm{HCN}$ and $\mathrm{CH}_{3} \mathrm{CN}$ : Constraints from aircraft measurements over the Western Pacific, J. Geophys. Res., 108(D21), 8827, doi:10.1029/2002JD003075, in press, 2003.

Liu, H., D. J. Jacob, I. Bey, R. M. Yantosca, B. N. Duncan, and G. W. Sachse, Transport pathways for Asian combustion outflow over the Pacific: Interannual and seasonal variations, J. Geophys. Res., 108(D20), 8786, doi:10.1029/2002JD003012, in press, 2003.

Lobert, J. M., W. C. Keene, J. A. Logan, and R. Yevich, Global chlorine emissions from biomass burning: Reactive Chlorine Emissions Inventory, J. Geophys. Res., 104, 8373-8389, 1999.

Martin, R. V., et al., Interpretation of TOMS observations of tropical tropospheric ozone with a global model and in situ observations, J. Geophys. Res., 108(D9), 4351, doi:10.1029/2001JD001480, 2002.

Michel, C., J.-M. Gregoire, K. Tansey, I. Marengo, S. Fritz, L. Boschetti, and $\mathrm{C}$. Liousse, Biomass burning emission inventory from a satellite based approach: The ACE-Asia case study, paper presented at IGAC, Iraklion, Crete, 2002.

Palmer, P. I., D. J. Jacob, D. B. A. Jones, C. L. Heald, R. M. Yantosca, J. A Logan, G. W. Sachse, and D. G. Streets, Inverting for emissions of carbon monoxide from Asia using aircraft observations over the western Pacific, J. Geophys. Res., 108(D21), 8828, doi:10.1029/2002JD003397, in press, 2003.

Prins, E. M., J. M. Feltz, W. P. Menzel, and D. E. Ward, An overview of GOES-8 diurnal fire and smoke results for SCAR-B and the 1995 fire season in South America, J. Geophys. Res., 103, 31,821-31,836, 1998.

Robinson, J. M., Problems in global fire evaluation: Is remote sensing the solution?, in Global Biomass Burning, Atmospheric, Climatic and Biospheric Implications, edited by J. Levine, pp. 67-73, MIT Press, Cambridge, Mass., 1991.

Singh, H. B., et al., In situ measurements of $\mathrm{HCN}$ and $\mathrm{CH}_{3} \mathrm{CN}$ in the Pacific troposphere: Sources, sinks and comparisons with spectroscopic observations, J. Geophys. Res., 108(D20), 8795, doi:10.1029/2002JD003006, in press, 2003.

Spichtinger, N., M. Wenig, P. James, T. Wagner, U. Platt, and A. Stohl, Satellite detection of a continental-scale plume of nitrogen oxides from boreal forest fires, Geophys. Res. Lett., 28, 4579-4582, 2001.

Stroppiana, D., S. Pinnock, and J.-M. Gregoire, The Global Fire Product: Daily fire occurrence from April 1992 to December 1993 derived from NOAA AVHRR data, Int. J. Remote Sens., 21, 1279-1288, 2000.

Thomas, W., E. Hegels, S. Slijkhuis, R. Spurr, and K. Chance, Detection of biomass burning combustion products in Southeast Asia from backscatter data taken by the GOME spectrometer, Geophys. Res. Lett., 25, $1317-$ 1320, 1998.

Wotawa, G., and M. Trainer, The influence of Canadian forest fires on pollutant concentrations in the United States, Science, 288, 324-328, 2000 .

D. R. Blake, Department of Chemistry, University of California, Irvine, Irvine, CA 92697-2025, USA. (drblake@uci.edu)

M. J. Evans, C. L. Heald, D. J. Jacob, and P. I. Palmer, Department of Earth and Planetary Sciences and Division of Engineering and Applied Sciences, Harvard University, Cambridge, MA 02138, USA. (mje@io. harvard.edu; heald@fas.harvard.edu; djacob@fas.harvard.edu; pip@io. harvard.edu)

G. W. Sachse, NASA Langley Research Center, Hampton, VA 23681, USA. (g.w.sachse@larc.nasa.gov)

H. B. Singh, NASA Ames Research Center, MS 245-5, Moffett Field, CA 94035, USA. (hsingh@mail.arc.nasa.gov) 

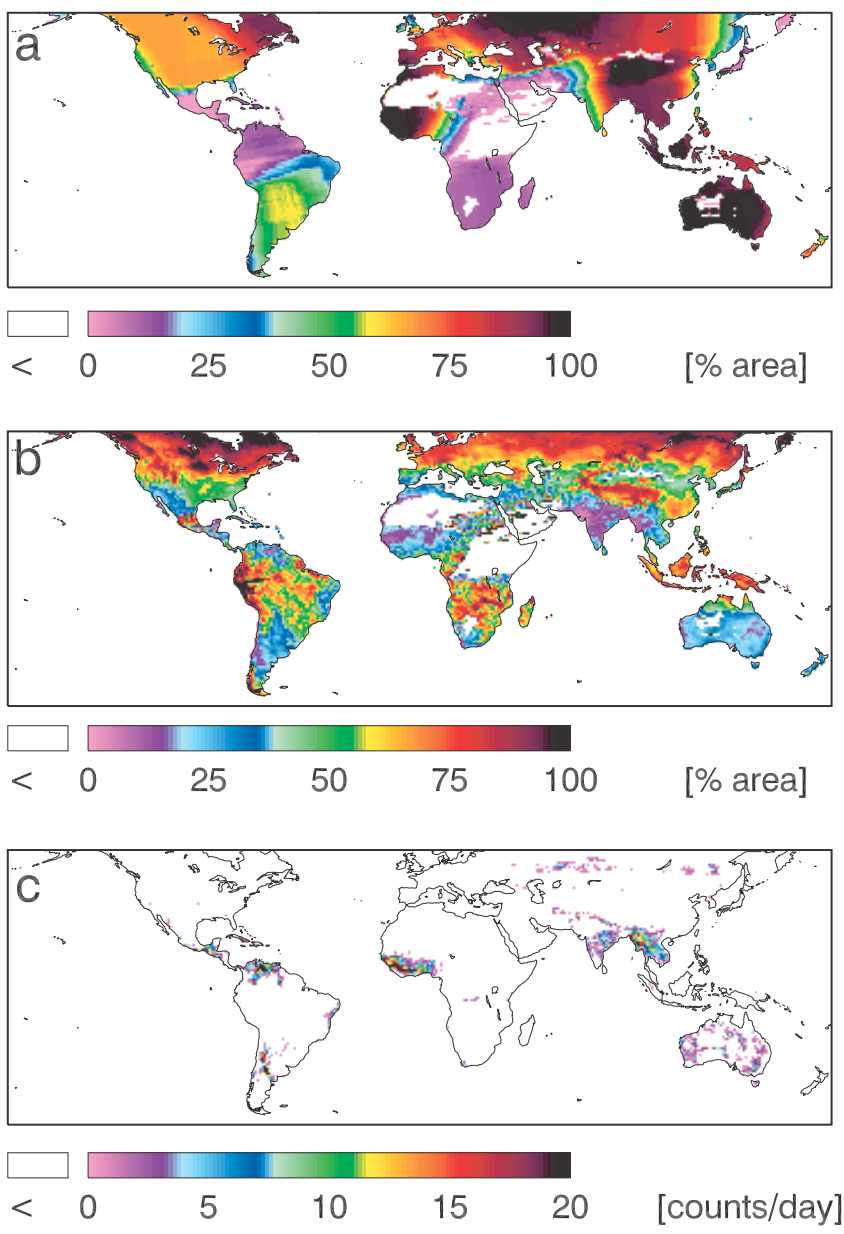

Figure 1. Mean statistics of the AVHRR World Fire Web product for February-April 2001, mapped on a $1^{\circ} \times 1^{\circ}$ grid. (a) Percentage of days with available data; (b) cloud cover; (c) daily fire counts. Blank areas have either no fires or no data. 

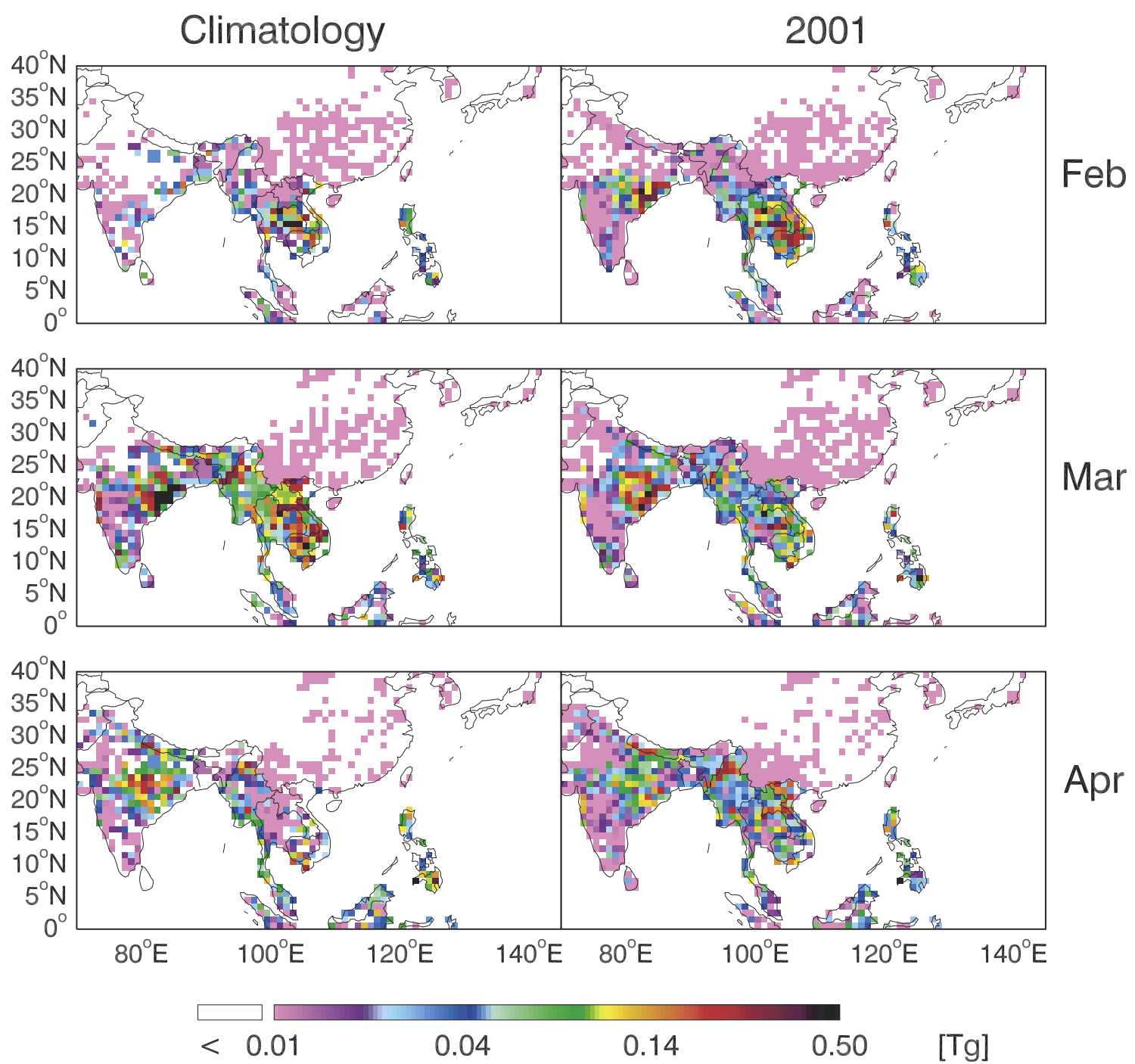

Figure 4. Climatological [Duncan et al., 2003] and 2001 AVHRR-derived monthly total CO emissions from biomass burning in East Asia in February-April. 



$5.1 \mathrm{~km}$
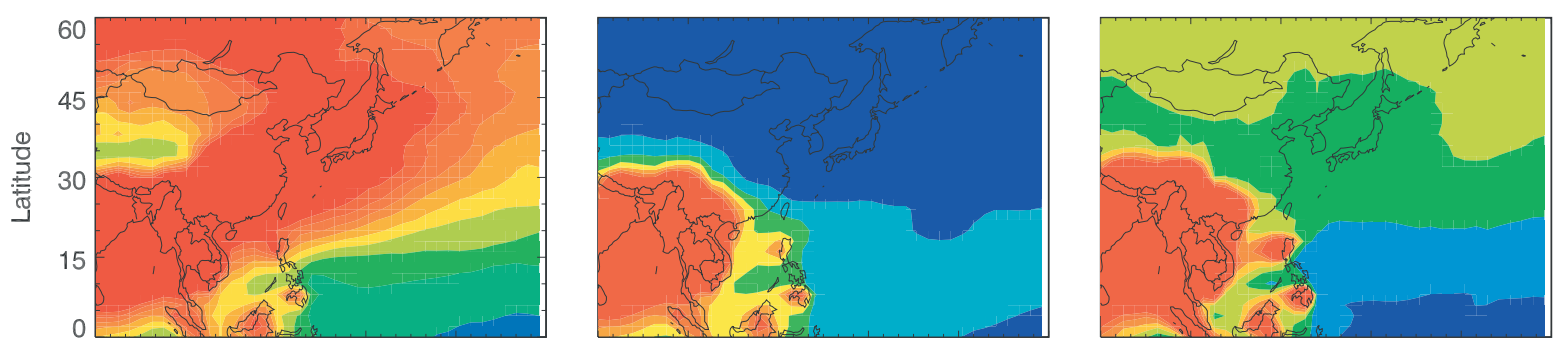

80

$\begin{array}{llllll}100 & 120 & 140 & 160 & 180 & 80\end{array}$

Longitude

$\begin{array}{lllllll}50 & 70 & 90 & 110 & 130 & 150 & {[p p b v]}\end{array}$
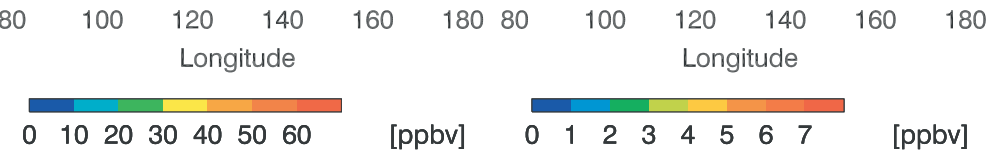

$1.1 \mathrm{~km}$

Figure 7. Simulated CO concentrations for the TRACE-P deployment period (25 February-10 April 2001) and effect of daily resolved biomass burning emissions. Left panels: mean CO concentrations at different altitudes in the 2001 daily simulation. The color bar is saturated at $150 \mathrm{ppbv}$ to emphasize the structure of the Asian outflow over the western Pacific sampled by TRACE-P; surface values over Asia can exceed 600 ppbv. Middle panels: mean biomass burning CO concentrations. The color bar is saturated at 60 ppbv. Right panels: average absolute differences between CO concentrations in the 2001 monthly and 2001 daily simulations. Color bar is saturated at 8 ppbv; absolute differences over Asia can exceed 120 ppbv. 


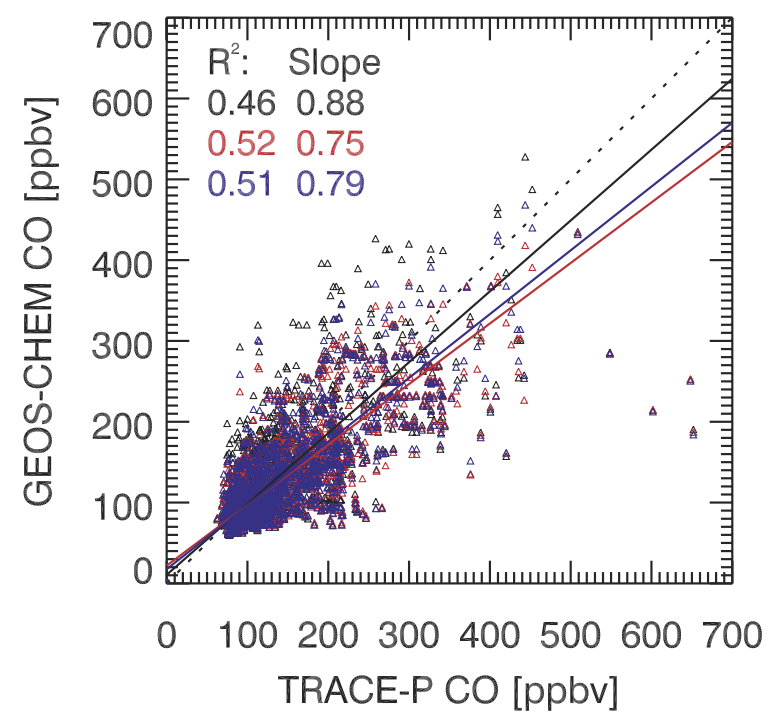

Figure 9. Point-by-point comparison of GEOS-CHEM model results to the ensemble of TRACE-P aircraft observations south of $30^{\circ} \mathrm{N}$ and west of the dateline. The lines of best fit for the climatological monthly (black) 2001 monthly (red) and 2001 daily (blue) simulations are shown. The one-to-one line is shown in dotted black. Statistics were computed with the reduced-major-axis method [Hirsch and Gilroy, 1984]. 